\title{
From Indicators to Composite Indexes: an Application of the Multi-Attribute Value Theory for Assessing Sustainability
}

\author{
Valentina Ferretti ${ }^{1, a}$, Marta Bottero ${ }^{1, b}$ and Giulio Mondini ${ }^{1, c}$ \\ ${ }^{1}$ Politecnico di Torino, Department of Regional and Urban Studies and Planning, Viale Mattioli 39, \\ 10125, Torino, Italy \\ avalentina.ferretti@polito.it, ${ }^{\circ}$ marta.bottero@polito.it, c'giulio.mondini@polito.it
}

\begin{abstract}
Keywords: Projects/Plans/Programmes, Policy Performance Index, Multicriteria Analysis, Swing method, Well-Being Indicators.
\end{abstract}

\begin{abstract}
The paper investigates the use of indicators in sustainability assessment of projects, plans and programmes and proposes an application of the Multi Attribute Value Theory (MAVT) for the definition of synthetic indexes of evaluation. With the aim of highlighting potentialities and limits of the proposed approach, the methodology is applied to a real case concerning a set of well-being indicators. The results of the study show that MAVT is suitable for dealing with the aggregation of indicators systems.
\end{abstract}

\section{Introduction}

The indicator is a parameter associated with a phenomenon, which can provide information on the characteristics of the event in its global form [1]. Its purpose is to indicate the state, or the variation in the state, of a phenomenon which cannot be measured directly. In fact the data, even if suitably presented, does not constitute an indicator, and can only be used as such when linked to a phenomenon other than that measured. Alone, an indicator provides little information unless it is associated with a system of indicators, able to provide systematic information for the purpose of assessment. A system of indicators consists of several indicators correlated from a logical and functional point of view, able to describe and provide information on several phenomena associated with each other, or which need to be interpreted in a coordinated way. One consolidated instrument for the integrated analysis of the social-economic and environmental aspects in the field of sustainability assessment is the system of environmental indicators known as the DPSIR model (Driving forces, Pressures, State, Impacts and Responses) [2].

Furthermore, one indicator alone cannot express the complexity of the system being observed, but it is possible to observe that a system of partial and extremely incoherent indicators can be an obstacle in the assessment procedure. Therefore, synthetic indexes can be defined, based on a combination of the information with reference to a multitude of indicators, able to express a value which represents the phenomenon being studied. The importance of defining synthetic indexes through the aggregation of several different indicators (even with the loss of information as a result of said aggregation), is clearly expressed by all experts in strategic assessment who must, due to the nature of these procedures, be able to make judgements on compatibility very quickly.

The main methodological reference for the aggregation of a system of partial indicators in an overall index is the approach based on the performance index. Particularly, the Policy Performance Index was drawn up by Jochen Jesinghaus in 1999 [3] to integrate classic social-economic indicators (GNP, inflation rate, employment) with new elements (in particular concerning environmental policies) in the assessment of the success or failure of certain policies [4].

\section{Multi Attribute Value Theory}

When dealing with sustainability assessments by means of indicators systems, a key question concerns the way according to which the various indicators used to determine the multidimensional value of courses of action can be integrated into a single index that measures the sustainability of the 
transformation as a whole. In the present study we propose the use of a Multi-Attribute Value Theory (MAVT) approach [5] for the aggregation of environmental and social indicators into a sustainability index for the Italian regions.

MAVT can be used to address problems that involve a finite and discrete set of alternative options that have to be evaluated on the basis of conflicting objectives. By being able to handle quantitative as well as qualitative data, MAVT plays a very crucial role in the field of environmental decision-making where many aspect are often intangible.

From the methodological point of view, the process to be followed to build a MAVT model can be described as follows:

\section{Defining and structuring the fundamental objectives and related attributes.}

Objectives are "statements of something that one desires to achieve"[6] and they depend on the problem to be analysed, on the actors involved in the decision process, and on the environment in which the decision process takes place. The degree to which objectives are achieved is measured through a set of attributes, which may be natural (they follow directly from the definition of the objective), constructed (they specify a finite number of degrees to which objectives are met), and proxy (they are only indirectly linked to the definition of the objective) $[6,7]$.

2. Identifying and creating alternative options.

The alternatives are the potential solutions to the decision problem. Methods and models such as visioning, problem structuring methods and scenario planning can help to promote creativity for the generation of good strategies and strategic options [8].

3. Assessing the scores for each alternative in terms of each attribute.

The performances of each alternative specify for each attribute the outcome of the alternative. In some cases, the performances are readily available, in some other cases they have to be computed or estimated ad hoc for the problem at hand [7].

4. Modelling preferences and value trade-offs.

Besides the multiattribute profiles under evaluation (i.e. the decision alternatives), the information items that play a role in a multiattribute value function model are the marginal value functions (which translate the performances of the alternatives into a value score representing the degree to which a decision objective is achieved), the weights (i.e. scaling constants), and the multiattribute value function which associates an overall value with each alternative. By aggregating the options' performance across all the attributes to form an overall assessment, MAVT is thus a compensatory technique.

5. Ranking of the alternatives.

MAVT includes different aggregation models, but the simplest and most used one is the additive model [9] as it is represented in equation (1):

$$
V(a)=\sum w_{i} \times v_{i}\left(a_{i}\right)
$$

where $V(a)$ is the value given to alternative $a$ by taking into account all attributes simultaneously while $v_{i}\left(a_{i}\right)$ is the value reflecting alternative $a$ 's performance on attribute $i$, and $w_{i}$ is the weight assigned to reflect the importance of attribute $i$.

It is important to underline that different strategies are available for the development of a MAVT model. The holistic scaling and the decomposed scaling strategies are the most used in practice and the interested reader is referred to Beinat [7] for a detailed discussion of the two approaches.

\section{Application}

The BES report

The present paper proposes an application of the MAVT for aggregating several indicators into a composite index. In particular, the analysis makes use of data and indicators available from a scientific report named BES which was developed by the Italian Institute of Statistics with the aim of assessing the national well-being [10].

The interest in well-being measurement has been highlighted for the first time by the Commission on the Measurement of Economic Performance and Social Progress set up by the French president in 2008. After that, a growing number of nations and international organizations have started activities 
for the measurement of well-being and progress of the society with the final aim of identifying an holistic measurement of the key features of nations' social, economic, and environmental progress and of providing this information to different users and decision-makers [11].

As far as the Italian BES report is concerned, the indicators for the measurement of the national well-being have been organized according to 12 categories, namely 1) Health; 2) Education; 3) Work; 4) Economic well-being; 5) Social relationships; 6) Politics and institutions; 7) Safety; 8) Subjective well-being; 9) Landscape and cultural heritage; 10) Environment; 11) Research and innovation; 12) Quality of services. Mention has to be made to the fact the both quantitative and qualitative indicators have been considered in the aforementioned report. Moreover, the indicators have been evaluated at a regional scale.

An example of synthetic indexes: the quality of services

With the aim of illustrating the methodological proposal for the aggregation of the different indicators into a synthetic index, the category related to the quality of services of the BES report will be considered. The set of indicators proposed by the BES report for the analysis of the services include different aspects, such as availability of infrastructures and accessibility of services.

According to the MAVT methodology, the elicitation procedure consists in defining a value function for each indicator; this value function allows to scale the indicators between 0 and 1 in order to aggregate non-commensurable items. Table 1 describes the considered indicators and the related value functions while Table 2 illustrates the standardized scores of the original indicators according to the considered value functions.

Table 1 Elicitation of value functions for each indicator belonging to the set "quality of services"

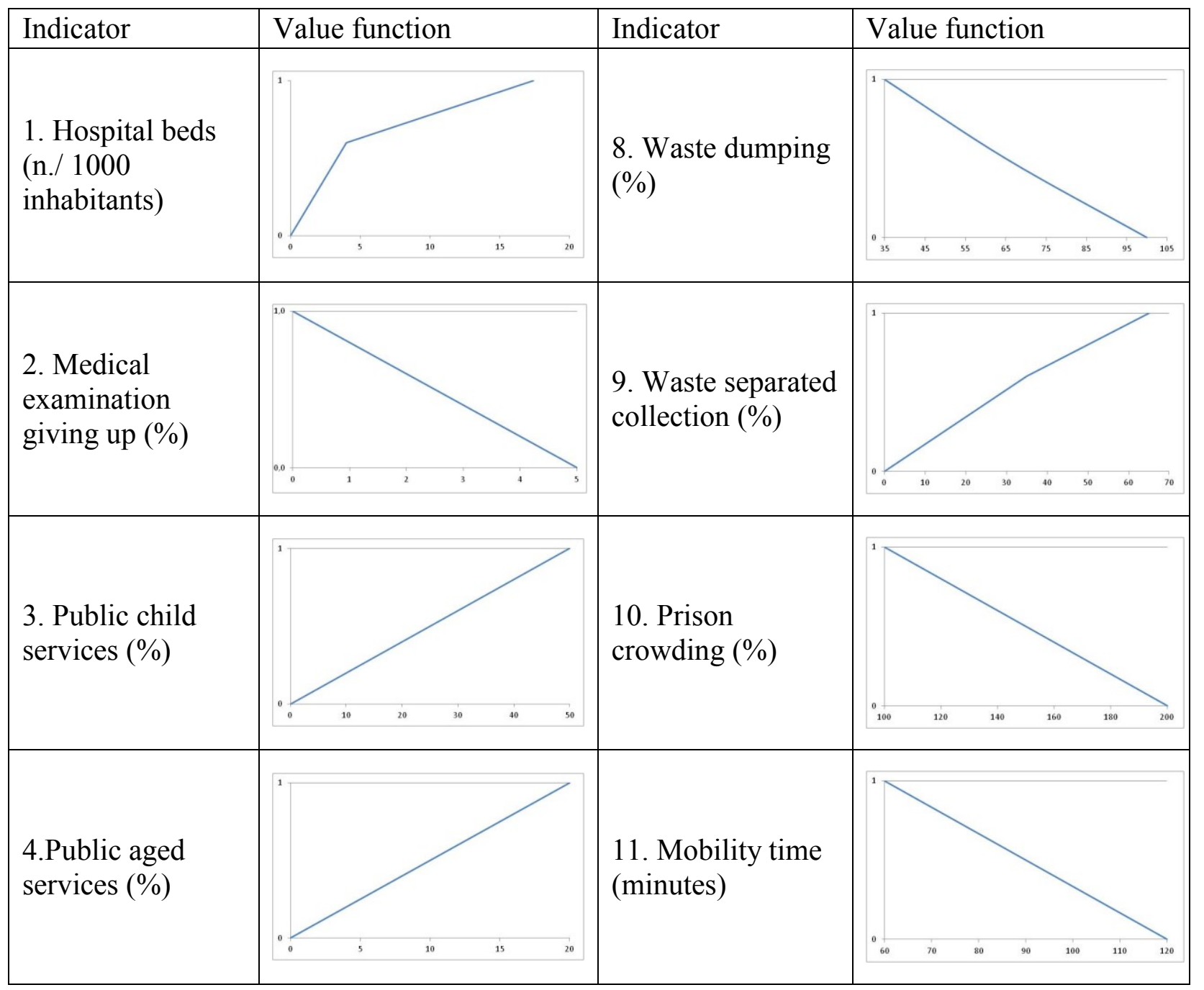




\begin{tabular}{|l|l|l|l|}
\hline Indicator & Value function & Indicator & Value function \\
\hline $\begin{array}{l}\text { 5. Electrical } \\
\text { network } \\
\text { interruption (\%) }\end{array}$ & $\begin{array}{l}\text { 12. Network } \\
\text { density }(\mathrm{km} \text { of } \\
\text { urban transport } \\
\left.\text { network } / 100 \mathrm{~km}^{2}\right)\end{array}$ \\
\hline 6. Gas supply (\%) & $\begin{array}{l}\text { 13.Services } \\
\text { accessibility (\% of } \\
\text { families for which } \\
\text { the accessibility of } \\
\text { basic services is } \\
\text { very difficult) }\end{array}$ \\
\hline $\begin{array}{l}\text { 7. Water network } \\
\text { interruption (\%) }\end{array}$ & & & \\
\hline
\end{tabular}

Table 2 Standardized scores for the considered set of indicators

\begin{tabular}{|l|c|c|c|c|c|c|c|c|c|c|c|c|c|}
\hline Regions/Indicators & $\mathbf{1}$ & $\mathbf{2}$ & $\mathbf{3}$ & $\mathbf{4}$ & $\mathbf{5}$ & $\mathbf{6}$ & $\mathbf{7}$ & $\mathbf{8}$ & $\mathbf{9}$ & $\mathbf{1 0}$ & $\mathbf{1 1}$ & $\mathbf{1 2}$ & $\mathbf{1 3}$ \\
\hline Piemonte & 0,91 & 0,86 & 0,31 & 0,11 & 0,85 & 0,86 & 0,90 & 0,91 & 0,81 & 0,64 & 0,67 & 1,00 & 0,62 \\
\hline Valle d'Aosta & 1,12 & 0,52 & 0,54 & 0,02 & 0,89 & 0,36 & 0,94 & 0,68 & 0,67 & 0,45 & 0,82 & 1,00 & 0,87 \\
\hline Liguria & 0,90 & 0,52 & 0,33 & 0,18 & 0,82 & 0,86 & 0,94 & 0,23 & 0,44 & 0,33 & 0,68 & 0,71 & 0,55 \\
\hline Lombardia & 0,90 & 0,88 & 0,38 & 0,22 & 0,89 & 0,94 & 0,91 & 1,00 & 0,78 & 0,46 & 0,75 & 0,78 & 0,82 \\
\hline Trentino & 0,97 & 0,52 & 0,39 & 0,11 & 0,83 & 0,51 & 0,95 & 1,00 & 0,91 & 0,51 & 0,73 & 0,81 & 0,82 \\
\hline Bolzano & 0,96 & 0,52 & 0,35 & 0,02 & 0,85 & 0,36 & 0,96 & 1,00 & 0,86 & 1,00 & 0,68 & 0,43 & 1,00 \\
\hline Trento & 0,99 & 0,52 & 0,44 & 0,18 & 0,81 & 0,65 & 0,93 & 0,95 & 0,94 & 1,00 & 0,78 & 0,63 & 0,65 \\
\hline Veneto & 0,87 & 0,88 & 0,25 & 0,28 & 0,83 & 0,82 & 0,91 & 1,00 & 0,92 & 0,36 & 0,78 & 0,21 & 0,74 \\
\hline Friuli & 0,93 & 0,52 & 0,40 & 0,34 & 0,90 & 0,78 & 0,94 & 1,00 & 0,79 & 0,43 & 0,68 & 0,81 & 0,88 \\
\hline Emilia-Romagna & 0,89 & 0,88 & 0,59 & 0,58 & 0,87 & 0,93 & 0,91 & 1,00 & 0,77 & 0,59 & 0,68 & 0,62 & 0,69 \\
\hline Toscana & 0,79 & 0,70 & 0,42 & 0,12 & 0,84 & 0,82 & 0,82 & 0,89 & 0,62 & 0,73 & 0,77 & 0,91 & 0,75 \\
\hline Umbria & 0,75 & 0,88 & 0,55 & 0,39 & 0,85 & 0,83 & 0,86 & 0,03 & 0,55 & 0,78 & 0,78 & 0,61 & 0,64 \\
\hline Marche & 0,82 & 0,88 & 0,34 & 0,18 & 0,82 & 0,89 & 0,86 & 0,63 & 0,66 & 0,42 & 0,73 & 0,51 & 0,70 \\
\hline Lazio & 0,72 & 0,76 & 0,30 & 0,24 & 0,75 & 0,80 & 0,77 & 0,15 & 0,28 & 0,55 & 0,53 & 0,54 & 0,68 \\
\hline Molise & 0,76 & 0,76 & 0,19 & 0,25 & 0,78 & 0,90 & 0,77 & 0,68 & 0,48 & 0,75 & 0,87 & 0,26 & 0,53 \\
\hline Campania & 0,82 & 0,54 & 0,11 & 0,17 & 0,87 & 0,84 & 0,68 & 0,32 & 0,22 & 0,77 & 0,80 & 0,63 & 0,61 \\
\hline Puglia & 0,41 & 0,78 & 0,05 & 0,11 & 0,51 & 0,66 & 0,85 & 0,82 & 0,56 & 0,59 & 0,72 & 0,79 & 0,11 \\
\hline Basilicata & 0,50 & 0,58 & 0,09 & 0,09 & 0,74 & 0,76 & 0,81 & 0,03 & 0,25 & 0,31 & 0,73 & 0,64 & 0,25 \\
\hline Calabria & 0,65 & 0,76 & 0,15 & 0,25 & 0,85 & 0,70 & 0,88 & 0,32 & 0,23 & 0,97 & 0,72 & 0,28 & 0,01 \\
\hline Sicilia & 0,57 & 0,66 & 0,05 & 0,14 & 0,57 & 0,47 & 0,42 & 0,65 & 0,21 & 0,64 & 0,78 & 0,33 & 0,12 \\
\hline Sardegna & 0,76 & 0,52 & 0,11 & 0,08 & 0,56 & 0,52 & 0,47 & 0,49 & 0,16 & 0,72 & 0,83 & 0,61 & 0,04 \\
\hline
\end{tabular}

\section{Weighing and aggregation}

Once the alternatives have been evaluated, it is necessary to define the importance of the different attributes of the decision problem. In this case the SWING method [12] has been used which explicitly incorporates the attribute ranges in the elicitation question. In particular, the method asks to value each improvement from the lowest to the highest level of each attribute [8] by using a reference 
state in which all attributes are at their worst level and asking the interviewee to assign points (e.g. in the range $0-100)$ to states in which one attribute at a time moves to the best state. The weights are then proportional to these values. In this study the evaluation has been performed by a panel of experts with expertise in the field of environmental engineering, urban planning and economic evaluation.

Table 3 shows an extract of the questionnaire they had to answer with reference to the improvement of attribute 13 .

Table 3 Extract of the questionnaire for the elicitation of the swing weights

Hypothetical alternative No. 13

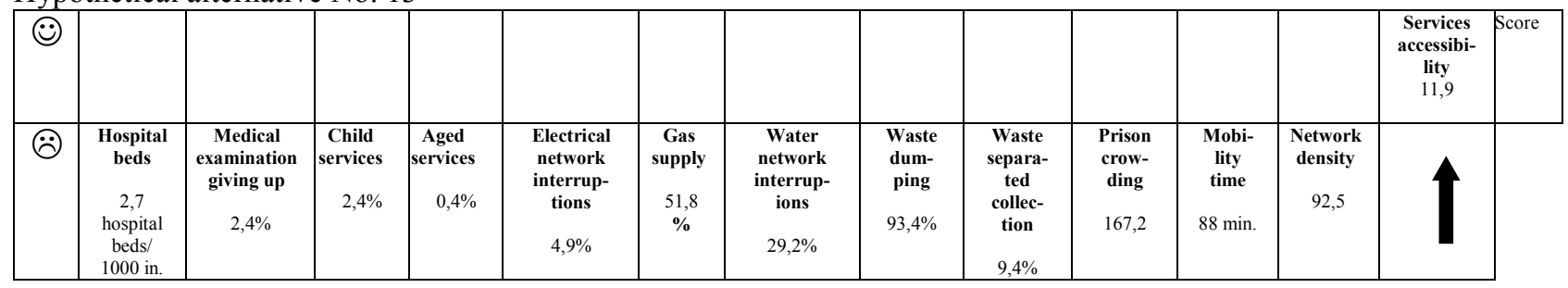

Worst hypothetical alternative

\begin{tabular}{|c|c|c|c|c|c|c|c|c|c|c|c|c|c|c|}
\hline$(-)$ & & & & & & & & & & & & & & $\begin{array}{c}\text { Score } \\
0\end{array}$ \\
\hline$\ddot{\theta}$ & $\begin{array}{c}\begin{array}{c}\text { Hospital } \\
\text { beds }\end{array} \\
2,7 \\
\text { hospital } \\
\text { beds/ } \\
1000 \mathrm{in} .\end{array}$ & $\begin{array}{c}\text { Medical } \\
\text { examination } \\
\text { giving up } \\
2,4 \%\end{array}$ & \begin{tabular}{|r}
$\begin{array}{c}\text { Child } \\
\text { services }\end{array}$ \\
$2,4 \%$
\end{tabular} & \begin{tabular}{|r}
$\begin{array}{c}\text { Aged } \\
\text { services }\end{array}$ \\
$0,4 \%$
\end{tabular} & $\begin{array}{c}\begin{array}{c}\text { Electrical } \\
\text { network }\end{array} \\
\text { interrup- } \\
\text { tions } \\
4,9 \%\end{array}$ & $\begin{array}{c}\text { Gas } \\
\text { supply } \\
\\
51,8 \%\end{array}$ & $\begin{array}{c}\begin{array}{c}\text { Water } \\
\text { network } \\
\text { interrup- } \\
\text { tions }\end{array} \\
29,2 \%\end{array}$ & $\begin{array}{r}\begin{array}{c}\text { Waste } \\
\text { dumping }\end{array} \\
93,4 \%\end{array}$ & $\begin{array}{c}\begin{array}{c}\text { Waste } \\
\text { separated } \\
\text { collection }\end{array} \\
9,4 \%\end{array}$ & \begin{tabular}{|r}
$\begin{array}{c}\text { Prison } \\
\text { crowding }\end{array}$ \\
167,2
\end{tabular} & $\begin{array}{c}\begin{array}{c}\text { Mobility } \\
\text { time }\end{array} \\
88 \mathrm{~min} .\end{array}$ & $\begin{array}{c}\begin{array}{c}\text { Network } \\
\text { density }\end{array} \\
92,5\end{array}$ & $\begin{array}{c}\text { Servi- } \\
\text { ces } \\
\text { acces- } \\
\text { sibility } \\
3 \\
3\end{array}$ & \\
\hline
\end{tabular}

In this case, the two alternatives are different only for the indicator "Services accessibility". For this reason, the score given by the interviewee to the hypothetical alternative represents how important is the improvement of that attribute for him.

The overall set of weights resulting from the elicitation procedure is shown in Table 3.

Table 3 Normalized weights resulting from the Swing Weight elicitation procedure

\begin{tabular}{|c|c|c|c|c|c|c|c|c|c|c|c|c|c|}
\hline Indicators & 1 & 2 & 3 & 4 & 5 & 6 & 7 & 8 & 9 & 10 & 11 & 12 & 13 \\
\hline $\begin{array}{c}\text { Weights } \\
(\%)\end{array}$ & 11,72 & 7,81 & 10,42 & 6,51 & 5,21 & 5,21 & 5,21 & 3,91 & 3,91 & 8,46 & 11,07 & 7,55 & 13.02 \\
\hline
\end{tabular}

The single attribute value functions have then been aggregated using the obtained set of weights according to equation (1). Table 4 shows the final ranking of the alternatives.

Table 4 Final ranking of the regions under analysis with reference to the "quality of services" index

\begin{tabular}{|l|c|c|l|c|c|l|c|c|}
\hline Regions & $\begin{array}{c}\text { Overall } \\
\text { value }\end{array}$ & Ranking & Regions & $\begin{array}{c}\text { Overall } \\
\text { value }\end{array}$ & Ranking & Regions & $\begin{array}{c}\text { Overall } \\
\text { value }\end{array}$ & Ranking \\
\hline Piemonte & 70,10 & 6 & Veneto & 65,23 & 11 & Molise & 60,58 & 13 \\
\hline Valle d'Aosta & 71,39 & 4 & Friuli & 70,72 & 5 & Campania & 58,71 & 14 \\
\hline Liguria & 58,32 & 15 & Emilia-Romagna & 74,44 & 1 & Puglia & 48,41 & 18 \\
\hline Lombardia & 72,80 & 2 & Toscana & 70,04 & 7 & Basilicata & 43,83 & 20 \\
\hline Trentino & 68,79 & 9 & Umbria & 67,60 & 10 & Calabria & 49,97 & 17 \\
\hline Bolzano & 69,91 & 8 & Marche & 64,22 & 12 & Sicilia & 42,34 & 21 \\
\hline Trento & 71,57 & 3 & Lazio & 56,28 & 16 & Sardegna & 45,65 & 19 \\
\hline
\end{tabular}




\section{Conclusions and future developments}

The results of the performed analysis show that MAVT represents a very useful tool for sustainability assessments [13] based on indicators and indexes. Particularly, one of the most significant strengths of the MAVT methodology is represented by the fact that the Decision Makers and stakeholders gain more awareness of the elements at stake while structuring the model and thus learn about the problems while solving them. Moreover, MAVT can deal with a large number of alternatives without an increase of the elicitation effort compared to a study with a smaller number of alternatives. This is due to the fact that value functions are elicitated from the Decision Maker or stakeholder independently of the alternatives. This last aspect is particularly important when dealing with regional and national sustainability ranking that could need to be updated periodically. However, eliciting preference functions for complex decisions with many objectives is intellectually challenging and time consuming. Future developments of the present research refer to the investigation of also other aggregation rules.

\section{Acknowledgments}

The paper is the result of the joint work of the three authors. Despite the overall responsibility being equally shared, Marta Bottero is responsible for the "Introduction" paragraph and Valentina Ferretti is responsible for the "Multi Attribute Value Theory" paragraph. The "Application" paragraph is the result of the joint work of Marta Bottero and Valentina Ferretti while the abstract and the "Conclusions and future development" paragraph are the result of the joint work of the three authors.

\section{References}

[1] OECD - Organization for Economic Co-operation and Development, OECD Environmental Indicators. Development, measurement and use, Working paper (2003).

[2] EEA - European Environmental Agency, Europe's Environment. The Dobris Assessment, Working paper (1995)

[3] J. Jesinghaus: Indicators for decision making, Working paper (1999)

[4] M. Bottero: Indicators assessment systems, in: Landscape Indicators. Assessing and Monitoring the Landscape Quality, edited by C. Cassatella, A. Peano, Springer, Berlin (2011)

[5] R. L. Keeney, H. Raiffa: Decisions with Multiple Objectives: Preferences and Value Trade-offs, Wiley, New York (1976)

[6] R. L. Keeney: Value focused thinking, Harvard university press, Cambridge (1992)

[7] E. Beinat: Value functions for environmental management, Kluwer Academic Publishers, Dordrecht (1997)

[8] G. Montibeller, A. Franco: Decision and Risk Analysis for the Evaluation of Strategic Options, in: Supporting Strategy: Frameworks. Methods and Models, edited by F.A O'brien, R.G. Dyson, John Wiley \& Sons, Chichester (2007)

[9] V. Belton, T. J. Stewart: Multiple Criteria Decision Analysis: An Integrated Approach, Kluwer Academic Press, Boston (2002)

[10] ISTAT, BES 2013. Il benessere equo e sostenibile in Italia (2013), Information on http://www.istat.it/it/files/2013/03/bes_2013.pdf

[11] J. Rinne, J. Lyytimaki, P. Kautto: From sustainability to well-being: Lessons learned from the use of sustainabledevelopment indicators at national and EU level, Ecological Indicators 35 (2013), pp. 35- 42

[12] Von Winterfeldt \& Edwards: Decision analysis and behavioral research. Cambridge University Press, Cambridge, UK (1986)

[13] V. Ferretti, M. Bottero, G. Mondini: Decision making and cultural heritage: an application of the Multi Attribute Value Theory for the reuse of historical buildings, Journal of Cultural Heritage. Information on http://dx.doi.org/10.1016/j.culher.2013.12.007 